\title{
Hydrogels based on chemically modified poly(vinyl alcohol) (PVA-GMA) and PVA-GMA/chondroitin sulfate: Preparation and characterization
}

\author{
E. G. Crispim ${ }^{1}$, J. F. Piai ${ }^{1}$, A. R. Fajardo', E. R. F. Ramos ${ }^{2}$, T. U. Nakamura ${ }^{2}$, C. V. Nakamura ${ }^{2}$, \\ A. F. Rubira ${ }^{1}$, E. C. Muniz ${ }^{1 *}$ \\ ${ }^{1}$ Grupo de Materiais Poliméricos e Compósitos (GMPC), Departamento de Química, Universidade Estadual de Maringá \\ (UEM) - Av. Colombo 5790; CEP 87020-900 - Maringá, Paraná, Brazil \\ ${ }^{2}$ Laboratório de Microbiologia Aplicada aos Produtos Naturais e Sintéticos, Departmento de Análises Clínicas, \\ Universidade Estadual de Maringá (UEM) - Av. Colombo 5790; CEP 87020-900 - Maringá, Paraná, Brazil
}

Received 10 September 2011; accepted in revised form 30 November 2011

\begin{abstract}
This work reports the preparation of hydrogels based on PVA-GMA, PVA-GMA is poly(vinyl alcohol) (PVA) functionalized with vinyl groups from glycidyl methacrylate (GMA), and on PVA-GMA with different content of chondroitin sulfate (CS). The degrees of swelling of PVA-GMA and PVA-GMA/CS hydrogels were evaluated in distilled water and the swelling kinetics was performed in simulated gastric and intestinal fluids (SGF and SIF). PVA-GMA and PVAGMA/CS hydrogels demonstrated to be resistant on SGF and SIF fluids. The elastic modulus, $E$, of swollen-hydrogels were determined through compressive tests and, according to the obtained results, the hydrogels presented good mechanical properties. At last, the presence of CS enhances the hydrogel cell compatibility as gathered by cytotoxicity assays. It was concluded that the hydrogels prepared through this work presented characteristics that allow them to be used as biomaterial, as a carrier in drug delivery system or to act as scaffolds in tissue engineering as well.
\end{abstract}

Keywords: polymer gels, poly(vinyl alcohol), chondroitin sulfate, hydrogels, drug delivery

\section{Introduction}

By the most used definition, hydrogels are polymer networks, which are capable of absorbing and retaining large amounts of water and biological fluids [1, 2]. The physical and chemical features of hydrogels are extremely important for choice of their specific applications. Normally, the behavior of hydrogels depends of external conditions in which such materials are exposed. Thus, it is important to characterize the hydrogel properties in conditions similar to that it will be applied [3].

An often and important characteristic of hydrogels is the biocompatibility. Because of this, hydrogels had been applied in biomedical field. For instance, as prolonged or controlled drug delivery systems, contact lenses, biosensors, catheters, and tissue engineering and organ reconstruction scaffolds are exceedingly common $[4,5]$.

Hydrogels can be formed by either chemical or physical cross-linking process or just by entangling of polymer chains. Galactomannan, dextran, alginate, pectin, and chondroitin sulfate are good examples of natural polymers applied on hydrogel formulations. Among the synthetic ones, poly(vinyl alcohol) (or PVA), poly(hydroxyethyl methacrylate) (or polyHEMA), poly(ethylene oxide) (or PEO) and poly( $N$-isopropylacrylamide) (or PNIPAAm) may be cited $[6,7]$ from a plenty of others.

\footnotetext{
${ }^{*}$ Corresponding author, e-mail: ecmuniz@uem.br
}

(c) BME-PT 
By combining synthetic and natural polymers through either interpenetrating (IPN) or semi-interpenetrating (semi-IPN) networks, both the hydrogel physical and biocompatibility properties can be improved [8]. Furthermore, this approach may induce on hydrogel specific properties such as $\mathrm{pH}$ and/or temperature-sensitivity [6].

PVA is a synthetic hydrophilic polymer widely used in various areas, including foods, lacquers, resins and cosmetics industries [9-11]. In the pharmaceutical field, PVA acts as drug coating agent [12] and as material for surgical sutures. This wide applicability of PVA in such fields is due its low toxicity $\left(\mathrm{LD}_{50}, 15-20 \mathrm{~g} \cdot \mathrm{kg}^{-1}\right)$, not showing mutagenic, or clastogenic characteristics [10, 11]. PVA has large oral ingestion, and it is not absorbed by the gastrointestinal tract, enabling its application in the obtainment of drug carriers.

Specifically, PVA-based hydrogels may be prepared by either chemical or physical cross-linking. As a rule, multifunctional moieties capable of reacting with the PVA hydroxyl groups can be used as crosslinking agents for obtaining 3D PVA networks [13]. Although PVA can be easily cross-linked by contact with glutaraldehyde in acidic medium [14] such process presents limitations due to non-uniformity of the obtained matrix and to the severe toxicity of glutaraldehyde. PVA can also be physically crosslinked by repeated freezing-thawing cycles in aqueous solution, creating crystalline clusters that actuate as reticules $[15,16]$. The advantage of this process is the absence of moieties that could obliterate the biocompatibility. However, the PVA hydrogels obtained through freezing-thawing process are mechanically poorer and less thermally stable than those obtained by chemical cross-linking [15]. In addition, it is difficult to obtain physical gels in situ using this methodology.

PVA and several polysaccharides have been modified with acrylates and methacrylates by different ways [17-20]. The addition of unsaturations to polymers allows the reticulation of modified polymers without the addition of cross-linking agents [21-26]. The reaction may be carried out through the radical initiator pathway or by UV-light [27]. The esterification of part of hydroxyl groups of PVA by reaction with glycidyl methacrylate has been often used in our lab for modifying PVA obtaining PVA-GMA. The cross-linking reaction of PVA-
GMA in presence of CS, which is a mucopolysaccharide present in tissues and ligaments and a key component of cartilage [27], results in a semi-IPN hydrogel type.

In the present work, different 3D PVA-GMA matrices with CS entrapped were prepared aiming to tailor some mechanical properties as compared to respective PVA-GMA matrix. The initial expectance is that the presence of CS enhanced mechanical properties and the cell viability. Therefore, the goals were to prepare hydrogels based on PVAGMA and semi-IPN hydrogels based on PVAGMA/CS and to characterize their mechanical properties, water uptake capacity at $\mathrm{pH} 1.2$ and 7.5 buffers solutions and cytotoxicity to potentize their application in biomedical uses.

\section{Experimental}

\subsection{Materials}

Poly(vinyl alcohol) ( $M_{\mathrm{w}} 13-23 \mathrm{~kg} \cdot \mathrm{mol}^{-1}$, CAS 9003-20-7), $N, N, N^{\prime}, N^{\prime}$-tetramethylethylenediamine (TEMED, CAS 110-18-9) and sodium persulfate (SP, CAS 7775-27-1) were purchased from Aldrich; Glycidyl methacrylate (GMA, CAS 106-91-2) was purchased from Acros Organics (Belgium). Chondroitin sulfate (CS, CAS 9007-28-7) was kindly supplied by Solabia (Maringá, Brazil). Cell culture medium Dulbecco's Modified Eagle Medium (DMEM, Gibco, Invitrogen Corporation, New York, USA) and trypan blue (Sigma Chemical Co., St. Louis, Missouri, USA) were also used. All the reagents were used as received.

\subsection{PVA characterization}

PVA molar masses $\left(M_{\mathrm{w}}\right.$ and $\left.M_{\mathrm{n}}\right)$ were determined through gel size-exclusion chromatography (SEC) in an Ultra-hydrogel linear column attached to a HPLC Shimadzu apparatus with a refraction index detector. Aqueous solution of $\mathrm{NaNO}_{3}\left(0.1 \mathrm{~mol} \cdot \mathrm{L}^{-1}\right)$ was used as mobile phase at $0.5 \mathrm{~mL} \cdot \mathrm{min}^{-1}$ flow rate. Pullulan from Sodex Denko (Japan) was used as standard. The obtained value for $M_{\mathrm{w}}$ was $23.4 \mathrm{~kg} \cdot \mathrm{mol}^{-1}$ and for $M_{\mathrm{n}}$ was $11.3 \mathrm{~kg} \cdot \mathrm{mol}^{-1}$; thus, the raw PVA presented a polydispersity ca. 2.07.

The molar mass of CS was obtained by diluted solution-viscometry at $25^{\circ} \mathrm{C}$ using the MarkHouwink-Sakurada Equation $\left([\eta]=k M_{\mathrm{v}}^{a}\right)$ in aqueous solution with ionic strength of $0.2 \mathrm{M}$. The $k$ and $a$ constants used were equal to $5 \cdot 10^{-6}$ and 1.14 , 
respectively [28]. The obtained $M_{\mathrm{v}}$ value for CS was $19.9 \mathrm{~kg} \cdot \mathrm{mol}^{-1}$.

\subsection{PVA modification}

The procedures for chemical modifying of PVA with GMA were adopted according to previously published work [29]. Briefly, the modification of PVA was performed through the insertion of methacryloyl groups from GMA on the PVA chains, utilizing different molar [-OH(PVA)/GMA] ratios, at controlled temperature $\left(62^{\circ} \mathrm{C}\right)$ during $6 \mathrm{~h}$. The modification reaction was carried out in dimethyl sulfoxide (DMSO) and the obtained material was purified in acetone for removing the GMA not reacted. The reaction of PVA with GMA producing PVA-GMA was confirmed through ${ }^{1} \mathrm{H}$ NMR spectroscopy (data not shown here). The different degrees of substitution (DS) were calculated from ${ }^{1} \mathrm{H}$ NMR spectra obtained for the PVA-GMA according to work reported by Crispim et al. [29].

\subsection{Preparation of PVA-GMA and PVA-GMA/CS hydrogels}

Membrane and cylinder forms of PVA-GMA or PVA-GMA/CS hydrogels were prepared using PVA-GMA at different DS (2.5, 3.5 and 5.0\%) and requested amounts of CS. The amounts of PVAGMA and CS applied to form the hydrogels are described in Table 1.

Each hydrogel sample was prepared by mixing of aqueous solutions of PVA-GMA and CS, containing the amounts of PVA-GMA and CS described in Table 1, except for PVA-GMA100 sample. Furthermore, $0.2 \mathrm{~mL}$ of $0.57 \mathrm{~mol} \cdot \mathrm{L}^{-1}$ TEMED aqueous solution, as a catalytic agent, was introduced in each sample preparation. The mixtures were deoxygenated by $\mathrm{N}_{2}$ bubbling for 15 min under stirring. After this, $0.15 \mathrm{~mL}$ of aqueous solution of SP $\left(\mathrm{Na}_{2} \mathrm{~S}_{2} \mathrm{O}_{8}, 0.2 \mathrm{~g} \cdot \mathrm{L}^{-1}\right)$ was added in each mixture under strong stirring, and then each solution was quickly inserted between two acrylic plates sepa- rated by a $3 \mathrm{~mm}$ thick rubber gasket (to obtain membranes) or quickly transferred to 5 and $10 \mathrm{~mL}$ syringes (to obtain hydrogels with cylindrical shape). The hydrogels were stored by $24 \mathrm{~h}$ at room temperature $\left(\right.$ ca. $25^{\circ} \mathrm{C}$ ) for complete cross-linking. After, the hydrogels were washed in distilled water several times to remove the not reacted moieties. The procedures to prepare the hydrogels for PVA-GMA with DS equal to $2.5,3.5$, and $5.0 \%$ were the same.

\subsection{Fourier transformed infrared spectroscopy (FTIR)}

The samples PVA-GMA100, PVA-GMA90/CS10 and PVA-GMA67/CS33, with DS equal to 5.0\%, and pure CS were characterized by FTIR technique using an equipment (Shimadzu Scientific Instruments, Japan, Model 8300) operating in the region from 4000 to $500 \mathrm{~cm}^{-1}$ with resolution of $4 \mathrm{~cm}^{-1}$. Before the spectrum acquisition, each dried sample was blended with $\mathrm{KBr}$ powder and pressed into tablets.

\subsection{Degree of swelling}

The degree of swelling $(q)$ was estimated from the weight ratio (in grams) of the swollen hydrogel sample up to $48 \mathrm{~h}$ (at the equilibrium) related to its dry weight (in grams) according to Equation (1):

$q=\frac{w_{\mathrm{i}}-w_{0}}{w_{0}}$

where $w_{\mathrm{i}}$ is the weight of the swollen hydrogel samples and $w_{0}$ is the weight of the dry ones. So, the cylindrical hydrogels samples were deposited in a container with $50 \mathrm{~mL}$ of distilled water. After achieved the swelling equilibrium, the hydrogels were collected and maintained in an oven for $48 \mathrm{~h}$, at $40^{\circ} \mathrm{C}$. Next, they were transferred to desiccators under reduced pressure for $72 \mathrm{~h}$ or until constant weight. The measurements of $q$ were made in triplicate $(n=3)$.

Table 1. Amounts of PVA-GMA and CS applied to prepare the PVA-GMA and PVA-GMA/CS hydrogels, at a fixed DS

\begin{tabular}{|l|c|c|c|c|}
\hline \multirow{2}{*}{ Hydrogel } & \multicolumn{2}{|c|}{ Amounts } & Mass ratio & Total Mass \\
\cline { 2 - 5 } & PVA-GMA [g] & CS [g] & PVA-GMA:CS [\%] & PVA-GMA + CS [g] \\
\hline PVA-GMA100 & 2.50 & 0.000 & $100: 0$ & 2.500 \\
\hline PVA-GMA90/CS10 & 2.50 & 0.278 & $90: 10$ & 2.778 \\
\hline PVA-GMA80/CS20 & 2.50 & 0.625 & $80: 20$ & 3.125 \\
\hline PVA-GMA67/CS33 & 2.50 & 1.250 & $67: 33$ & 3.750 \\
\hline
\end{tabular}




\subsection{Determination of swelling kinetics in simulated gastric fluid (SGF) and simulated intestinal fluid (SIF)}

The hydrogel swelling kinetics was investigated in SGF (pH 1.2 \pm 0.1$)$ and SIF (pH 7.5 \pm 0.1$)$. SGF and SIF were prepared according to the United States Pharmacopeia (USP) [30], except the use of enzymes. For these tests, cylindrical hydrogels with approximately $15 \mathrm{~cm}$ diameter and $15 \mathrm{~mm}$ thickness were dried under reduced pressure until constant weight. Each sample was dipped in $50 \mathrm{~mL}$ of either SGF or SIF at $37^{\circ} \mathrm{C}$. So, each sample was weighed from 5 min after immersion in the desired time span up to constant weight. Swelling kinetics was evaluated using the Equation (2) [31]:

$\frac{M_{\mathrm{t}}}{M_{\infty}}=k t^{\mathrm{n}}$

where $M_{\mathrm{t}}$ and $M_{\infty}$ are the fluid mass absorbed by the hydrogel up to time $t$ and at equilibrium, respectively. The values of $k$ and $\mathrm{n}$ for each run were determined from the coefficients (linear and slope, respectively) of the curve $\ln \left(M_{\mathrm{t}} / M_{\infty}\right)$ versus $\ln t$.

\subsection{Compressive measurements}

Compressive tests were performed in hydrogels membranes using a texture analyzer (TA.TXT2 Stable Micro System, Haslemere, Surrey, UK) equipped with a $5 \mathrm{~kg}$ load cell. The maximum sample deformation was fixed at $1.0 \mathrm{~mm}$. Compressive tests were carried out by moving down a cylindrical probe with $12.7 \mathrm{~mm}$ diameter at $0.2 \mathrm{~mm} \cdot \mathrm{s}^{-1}$. The test (sample adjustment and compression) must be performed in less than $50 \mathrm{~s}$ for avoiding water loss by the hydrogel during the experiment. Prior to the tests, the hydrogel-membranes $(30 \mathrm{~mm} \times 50 \mathrm{~mm}$ and thickness $\approx 3 \mathrm{~mm}$ ) were immersed in distilled water for $48 \mathrm{~h}$ at $25^{\circ} \mathrm{C}$. The compressive tests using the swollen samples were carried out at $25^{\circ} \mathrm{C}$. For each sample, duplicate $(n=2)$ were performed and average value was calculated. The data generated by the equipment are force $(F)$ and strain $(\Delta L)$. Stress $(\sigma)$ was obtained through Equation (3):

$\sigma=\frac{F}{A}$

where $A$ is the cross-sectional area of the probe. The value of the compressive modulus $(E)$ of each hydrogel was calculated through Equation (4):
$E=\frac{\sigma}{\alpha-\alpha^{-2}}=R \operatorname{Tv}_{\mathrm{e}}\left(\frac{\varphi_{2, \mathrm{r}}}{\varphi_{2, \mathrm{~s}}}\right)^{2 / 3} \varphi_{2, \mathrm{~s}}$

from the initial linear portion of the curves of $\sigma$ versus $\left(\alpha-\alpha^{-2}\right)$, where $\alpha$ is the de ratio of strain given by $\alpha=\left(L_{0}+\Delta L\right) / L_{0}<1.10$, being $L_{0}$ the sample initial thickness.

The values of cross-linking density, $v_{\mathrm{e}}$, and the molar mass between two consecutive cross-links, $M_{\mathrm{c}}$, of PVA-GMA hydrogels without CS (or PVAGMA100) were calculated from the $G$ modulus using Equations (5) and (6):

$$
\begin{aligned}
& \nu_{\mathrm{e}}=\frac{G}{R T\left(\frac{\varphi_{2, \mathrm{r}}}{\varphi_{2, \mathrm{~s}}}\right)^{2 / 3} \varphi_{2, \mathrm{~s}}} \\
& M_{\mathrm{c}}=\frac{\rho_{2}}{\nu_{\mathrm{e}}+\frac{2 \rho_{2}}{M_{\mathrm{n}}}}
\end{aligned}
$$

where $G=3 / E$ [32], $\rho_{2}$ and $M_{\mathrm{n}}$ are the density and molecular mass of the polymer, respectively. The parameters $\varphi_{2, \mathrm{~s}}$ and $\varphi_{2, \mathrm{r}}$ calculated with the respective Equations (7) and (8):

$$
\begin{aligned}
& \varphi_{2, \mathrm{~s}}=\frac{V_{0}}{V_{\mathrm{s}}}=\frac{\frac{W_{0}}{\rho_{0}}}{\frac{W_{0}}{\rho_{0}}+\frac{W_{\mathrm{s}}-W_{0}}{\rho_{\mathrm{H}_{2} \mathrm{O}}}} \\
& \varphi_{2, \mathrm{r}}=\frac{V_{0}}{V_{\mathrm{r}}}=\frac{\frac{W_{0}}{\rho_{0}}}{\frac{W_{0}}{\rho_{0}}+\frac{W_{\mathrm{r}}-W_{0}}{\rho_{\mathrm{H}_{2} \mathrm{O}}}}
\end{aligned}
$$

where $V$ and $W$ are volume and mass, respectively, and subscripts $0, s$, and $r$ mean dry, equilibriumswelling, and relaxed (just after polymerization) states of hydrogel. The density of the dry hydrogel, $\rho_{0}$, was considered as being the density of atactic PVA, $1.269 \mathrm{~g} \cdot \mathrm{cm}^{-3}[33]$.

\subsection{Hydrogels morphologies}

The morphologies of hydrogels were evaluated through SEM images. PVA-GMA100, PVA-GMA90/ CS10 and PVA-GMA80/CS20 cylindrical hydrogels surface images were obtained in an $8 \mathrm{keV}$ scanning electron microscope (SEM, Shimadzu, model SS550). The hydrogels were firstly immersed in distilled water at room temperature $\left(\mathrm{ca} .25^{\circ} \mathrm{C}\right)$ up to 
swelling at equilibrium (ca. $48 \mathrm{~h}$ ). Next, the samples were removed and immediately frozen by dipping in liquid nitrogen. Thereafter, the frozen samples were fractured and lyophilized in a freeze dryer (Christ Gefriertrocknungsanlagen) at $-55^{\circ} \mathrm{C}$ for $24 \mathrm{~h}$. The lyophilized hydrogels were gold-coated by sputtering before the observation by SEM.

\subsection{Evaluation of cytotoxicity}

Hydrogel cytotoxicity was evaluated according to the ASTM-F813-01 [34] procedure in a similar way had done by Malmonge et al. [35]. Cylindrical hydrogels samples with $10 \mathrm{~mm}$ diameter and the controls, silicon (as positive) and HDPE plate (as negative), were cut in disc shape with $2 \mathrm{~mm}$ of thickness. The samples were swelled in distilleddeionized water for $48 \mathrm{~h}$. The water content was renewed every $6 \mathrm{~h}$. The hydrogels and controls were sterilized in autoclave $\left(121^{\circ} \mathrm{C}\right.$ for $\left.15 \mathrm{~min}\right)$. Each sample was placed in a cover slip in a Leighton tube and kept in $2 \mathrm{~mL}$ of DMEM medium supplemented with $10 \%$ Fetal Bovine Serum (FBS) for $24 \mathrm{~h}$ at $37^{\circ} \mathrm{C}$ in humidified $95 \%$ air $5 \% \mathrm{CO}_{2}$ $(\mathrm{v} / \mathrm{v})$ before the inoculation. An aliquot of Vero cell line $\left(1 \mathrm{~mL}\right.$ - conc. equal to $10^{5}$ cells $\left.\cdot \mathrm{mL}^{-1}\right)$ was transferred to each Leighton tube and cultivated in DMEM containing 10\% FBS. The samples were incubated at $37^{\circ} \mathrm{C}$ for $48 \mathrm{~h}$ in humidified $95 \%$ air $5 \% \mathrm{CO}_{2}$. After a period of $48 \mathrm{~h}$ from the incubation, the culture media were collected and unviable cells were assessed by trypan blue dye (conc. equal to $0.1 \%$ in $0.9 \%$ salt) exclusion test in a Neubauer chamber.

\section{Results and discussion}

All hydrogels synthesized in this work show opacity, indicating that PVA-GMA is less hydrophilic than raw PVA is. All PVA-GMA67/CS33 hydrogel preparation runs resulted in irregular bubbly material, which was attributed to the high viscosity of the feed solutions used for the synthesis. In this way, the obtained PVA-GMA67/CS33 hydrogels were very fragile. Thus, tests for determinate the mechanical properties and the swelling kinetics assays on PVA-GMA67/CS33 hydrogel were not performed. According to our laboratory's previous work [29], in the optimized conditions $\left(62^{\circ} \mathrm{C}\right.$ and $6 \mathrm{~h})$ the achieved DS for the chemical modification of PVA with GMA was $4.63 \%$ while the expected was $4.85 \%$ [29]. Additionally, it was found that in these optimized conditions the DS changed linearly with the [-OH(PVA)/GMA] ratio up to $1 / 0.25$ [29]. Thus, in this work, it was assumed that the DS of the all PVA-GMA used in the hydrogel synthesis was the same as the nominal ones.

\subsection{FTIR spectroscopy}

The Figure 1a-d shows the FTIR spectra of PVAGMA100, PVA-GMA90/CS10, PVA-GMA67/CS33 hydrogels, and pure CS, respectively. The FTIR spectroscopy technique was applied to characterize the insertion of CS within the hydrogel matrix. For this reason, FTIR spectra of the hydrogels with the higher and lower amounts of CS (PVA-GMA90/ CS10 and PVA-GMA67/CS33) were obtained. The FTIR spectrum of PVA-GMA100 hydrogel (Figure 1a) presents a broad band at $3421 \mathrm{~cm}^{-1}$ assigned to the $-\mathrm{OH}$ stretching, a band at $2936 \mathrm{~cm}^{-1}$ assigned to $\mathrm{C}-\mathrm{H}$ vibrational stretching, and a band at $1094 \mathrm{~cm}^{-1}$ assigned to $\mathrm{C}-\mathrm{O}$ vibrational stretching. Moreover, the bands at 1727 and $1642 \mathrm{~cm}^{-1}$, which are assigned to $\mathrm{C}=\mathrm{O}$ and $\mathrm{C}=\mathrm{C}$ stretching, proceeding from methacrylate groups of GMA used for modifying PVA [36].

The FTIR spectrum of CS (Figure 1d) shows a broad band between $3100-3600 \mathrm{~cm}^{-1}$ assigned to $-\mathrm{OH}$ and to $\mathrm{N}-\mathrm{H}$ vibrational stretching in which the $-\mathrm{OH}$ stretching overlaps the $\mathrm{N}-\mathrm{H}$ one. The bands close to 1650 and $1050 \mathrm{~cm}^{-1}$ were assigned to amide bands and to $\mathrm{C}-\mathrm{O}$ vibration stretching respectively. A quite broad band appears at $1424 \mathrm{~cm}^{-1}$, which was assigned to $\mathrm{C}-\mathrm{O}$ stretching and $\mathrm{O}-\mathrm{H}$ angular coupling vibration. This band indicates the exis-

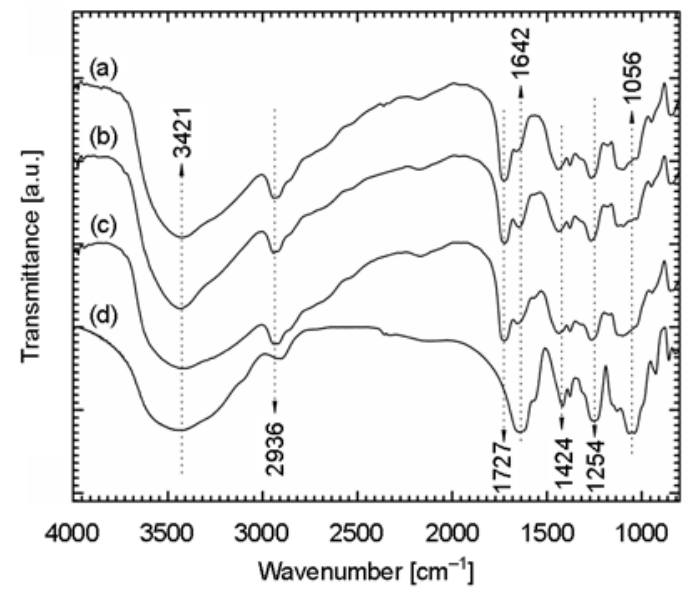

Figure 1. FTIR spectra of (a) PVA-GMA100, (b) PVAGMA90/CS10, (c) PVA-GMA67/CS33 hydrogels and (d) pure CS 


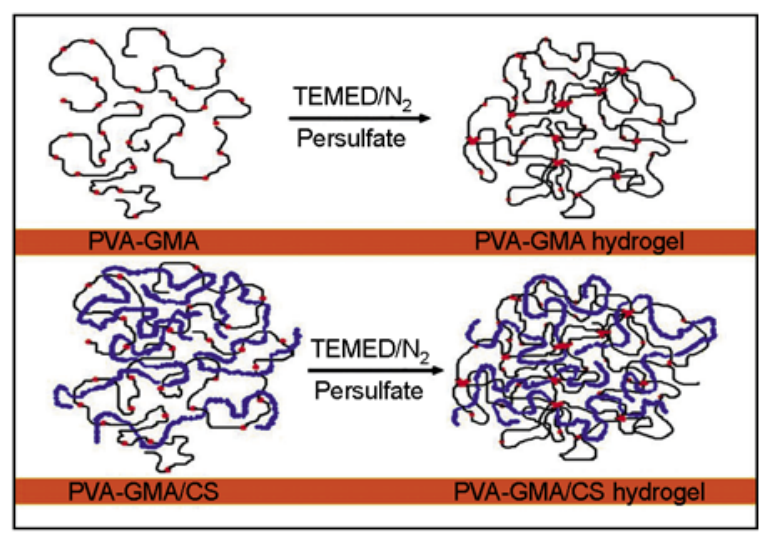

Figure 2. Scheme for the synthesis of PVA-GMA hydrogel (above) and PVA-GMA/CS semi-IPN hydrogel (below)

tence of free carboxyl groups. The band assigned to the vibrational stretching of $\mathrm{S}=\mathrm{O}$ bonds from sulfate groups, characteristic of CS, appears at $1254 \mathrm{~cm}^{-1}$. Figure 1b-c shows the FTIR spectra of PVA-GMA90/ CS10, PVA-GMA67/CS33 hydrogels and comparing with the PVA-GMA100 spectrum it was not observed significant changes caused by CS insertion within the hydrogel matrix. It was observed an enlargement of the band assigned to - $\mathrm{OH}$ stretching according to increase of the amount of CS in the hydrogel formulation. Furthermore, an increase in the intensity of the band at $1642 \mathrm{~cm}^{-1}$, assigned to the amide bands from CS, was observed. The semiIPN hydrogel is formed by the crosslinking of PVAGMA and the CS remains in linear form within the matrix, as sketched in the Figure 2. For this reason, great changes on PVA-GMA/CS FTIR spectra related to PVA-GMA100 FTIR spectrum were not observed.

\subsection{Degree of swelling}

All hydrogels samples achieve the equilibrium swelling at immersion times lower than $48 \mathrm{~h}$. The dependence of $q$ to DS of parent PVA-GMA for PVA-GMA100, PVA-GMA90/CS10, PVA-GMA80/ CS20, and PVA-GMA67/CS33 hydrogels, at $25^{\circ} \mathrm{C}$, is shown in Figure 3. As expected, the $q$ values decrease as the DS increases. This fact was attributed to the augment in the degree of cross-linking in the hydrogel matrix due to DS rising. Higher DS means high amount of methacrylate groups attached on PVA chains. These reactive groups are likely to react during gelling reaction, as they react with each other to form a cross-linking point. The increase in

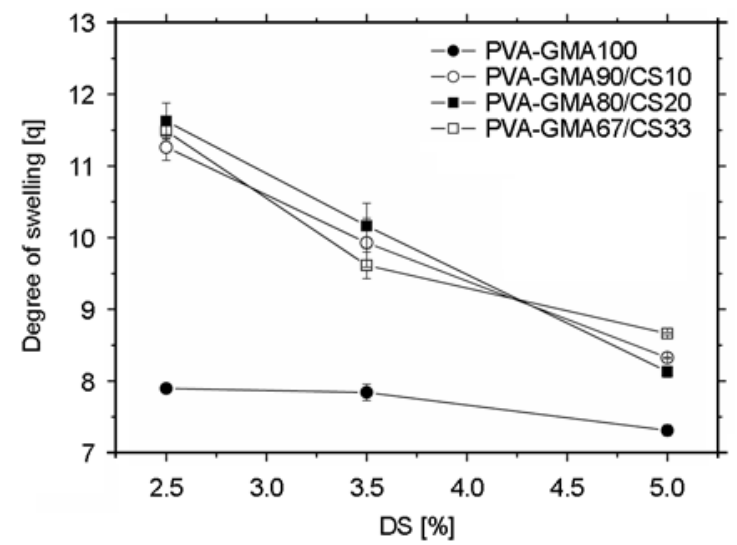

Figure 3. Degree of swelling as a function of DS of PVAGMA presents in the hydrogel samples: PVAGMA100, PVA-GMA90/CS10, PVA-GMA80/ CS20, and PVA-GMA67/CS33

the cross-linking degree limits the matrix expansion and then lesser water amount is absorbed, reducing the $q$ value.

The reduction in $q$ as the DS increases is less significant in PVA-GMA100 hydrogels than those containing CS. At a fixed DS, the hydrogels containing CS presented high $q$ values comparatively to the respective PVA-GMA100, fact attributed to the substantial hydrophilic character of CS. This is a detachable feature presented by the glycosaminoglycans, that constitutes the extracellular matrix and conjunctive tissues, which presents excellent water uptake and retention capabilities [27]. However, no significant difference was observed in $q$ values for PVA-GMA/CS hydrogels, at fixed DS, even using different amounts of CS $(10<\mathrm{CS}<$ $33 \mathrm{wt} \%$ ).

The swelling data allow inferring that the mobility of PVA-GMA chains governs the effect of CS on $q$ values of PVA-GMA/CS hydrogels. In this case, using the PVA-GMA with low DS would let the hydrogel to have both large chain mobility and high water uptake. However, the PVA-GMA chain mobility itself (absence of CS) is not enough to raise the $q$ value as occurred when CS is present in the matrix. It should be highlighted that the CS chains are not covalently bound to the PVA-GMA matrix. Based on Figure 3, it can be inferred that highly crosslinked PVA-GMA/CS hydrogels would present $q$ values closer to those of their respective PVAGMA. Therefore, in highly cross-linked PVA-GMA/ CS the effect of CS in $q$ was weakened. 


\subsection{Hydrogel mechanical properties}

The curves of compressive stress $(\sigma)$ as a function of $\left(\alpha-\alpha^{-2}\right)$ for PVA-GMA100 and PVA-GMA90/ CS10 hydrogels are presented in the Figures $4 \mathrm{a}$ and $4 \mathrm{~b}$, respectively, at three different DS [DS $=2.5,3.5$ and $5.0 \%$ ] of PVA-GMA.

The curves are almost linear, which indicates that the compressive tests produce predominantly elastic (reversible) deformations in the studied range of strain $(0 \leq \alpha \leq 1.10)$. Thus, the value of elastic modulus, $E$, for each hydrogel was obtained from the slope of the $\sigma v s$. $\left(\alpha-\alpha^{-2}\right)$ curve, as those shown in the Figures $4 \mathrm{a}$ and $4 \mathrm{~b}$. Figure 5 shows the dependence of $E$ to the nominal DS of PVA-GMA for PVAGMA100, PVA-GMA90/CS10, and PVA-GMA80/ $C S 20$. The values of $E$ ranged from 63 to $126 \mathrm{kPa}$. Peppas and Merrill [37] obtained wider range for $E$ values (31 to $340 \mathrm{kPa}$ ) using PVA hydrogels crosslinked by electron beam irradiating $10 \mathrm{wt} \%$ polymer aqueous solution. These authors observed that for those polymers the value of $E$ depends on the radiation dose due to its effect in the degree of cross-linking.

The PVA-GMA hydrogels obtained using PVAGMA with DS $=5.0 \%$ were more rigid and thus presented high $E$ values. Compared to PVA-GMA hydrogels, the presence of CS in the hydrogels lowered the values of $E$ modulus, which agrees with the

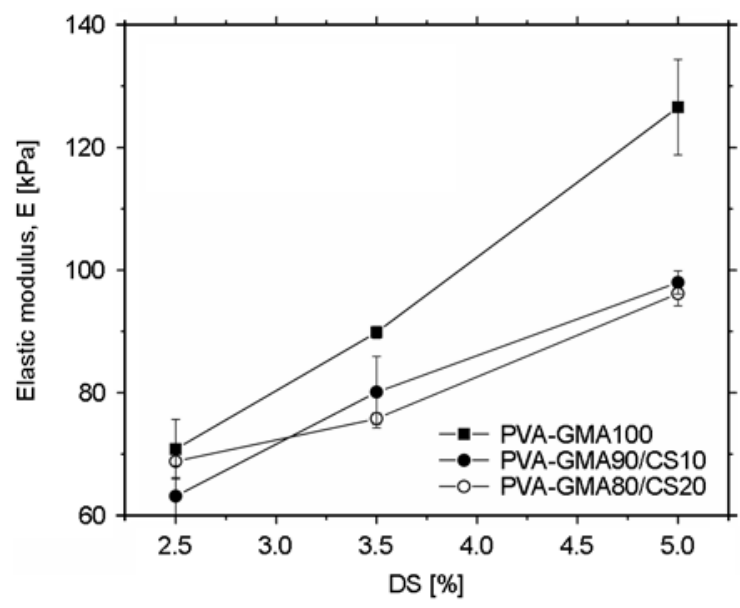

Figure 5. Elastic modulus, $E$, as a function of DS to PVAGMA100, PVA-GMA90/CS10 and PVA-GMA80/ 20 hydrogels samples

swelling data presented in the Figure 3. Figure 5 shows that $E$ of PVA-GMA100 increases by ca. $80 \%$ as the DS of PVA-GMA changes from 2.5 to $5.0 \%$, while the Figure 3 shows that, for the same hydrogels and DS range, the variation in $q$ values is only $7 \%$. Therefore, besides the PVA-GMA DS has little and negative effect on the $q$ of PVA-GMA100 hydrogels it induces a strong rise in their elastic modulus.

The cross-linking density, $v_{\mathrm{e}}$, and the molar mass between two consecutive cross-links, $M_{\mathrm{c}}$, were calculated with Equations (5) and (6), respectively.

Table 2. Cross-linking density, $v_{\mathrm{e}}$, molar mass between cross-links, $M_{\mathrm{c}}$, shear modulus, $G$, and volumetric fractions $\left(\varphi_{2, \mathrm{r}}\right.$ and $\left.\varphi_{2, \mathrm{~s}}\right)$ of PVA-GMA100 at different DS values measured at $25^{\circ} \mathrm{C}$

\begin{tabular}{|l|c|c|c|c|c|}
\hline $\mathbf{D S}[\mathbf{\%}]$ & $\boldsymbol{\varphi}_{2, \mathbf{r}}$ & $\boldsymbol{\varphi}_{2, \mathbf{s}}$ & $\mathbf{G}[\mathbf{k P a}]$ & $\mathbf{v}_{\mathbf{e}}\left[\mathbf{m o l} \cdot \mathbf{m}^{\mathbf{- 3}}\right]$ & $\mathbf{M}_{\mathbf{c}}\left[\mathbf{g} \cdot \mathbf{m o l}^{-\mathbf{1}}\right]$ \\
\hline 2.5 & $0.1051 \pm 0.0002$ & $0.1026 \pm 0.0003$ & $23.60 \pm 1.62$ & $91.4 \pm 6.3$ & $4590 \pm 104$ \\
\hline 3.5 & $0.1049 \pm 0.0017$ & $0.1033 \pm 0.0016$ & $29.95 \pm 0.32$ & $115.9 \pm 3.0$ & $4214 \pm 43$ \\
\hline 5.0 & $0.1122 \pm 0.0015$ & $0.1110 \pm 0.0012$ & $42.19 \pm 2.59$ & $152.4 \pm 11.2$ & $3762 \pm 125$ \\
\hline
\end{tabular}
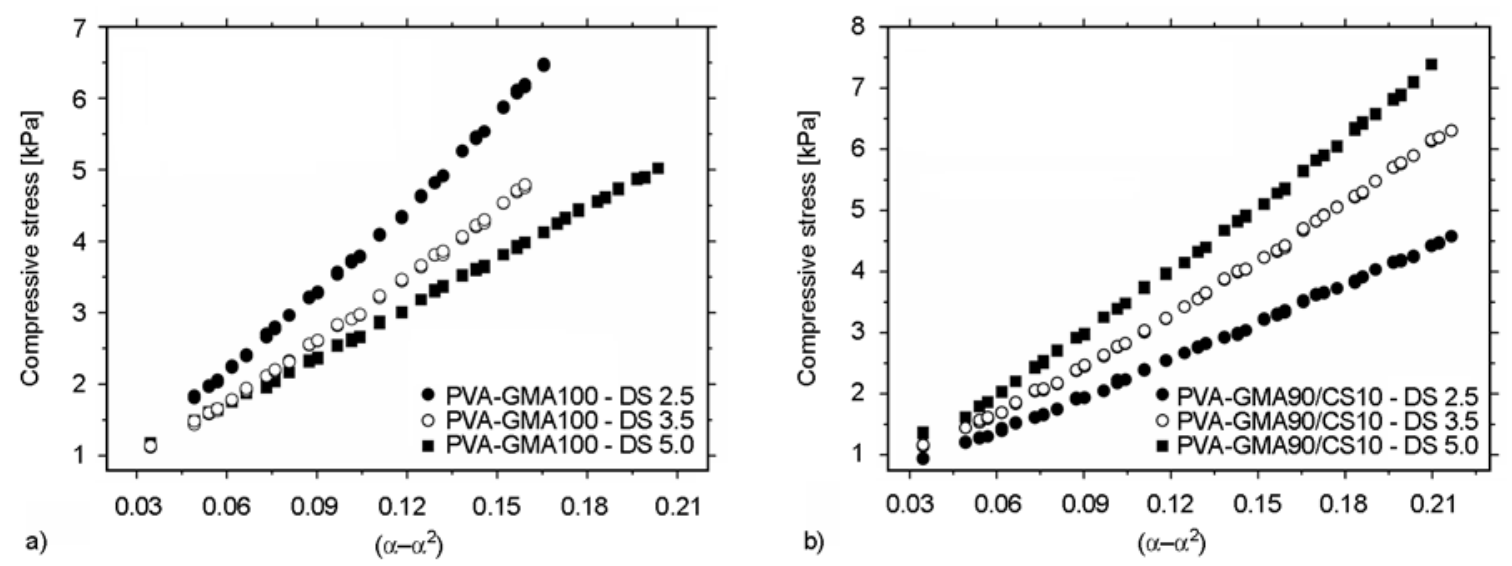

Figure 4. Compressive stress as a function of $\left(\alpha-\alpha^{-2}\right)$ of PVA-GMA100 (a) and PVA-GMA90/CS10 (b) at DS equal to 2.5, 3.5 , and $5.0 \%$ 


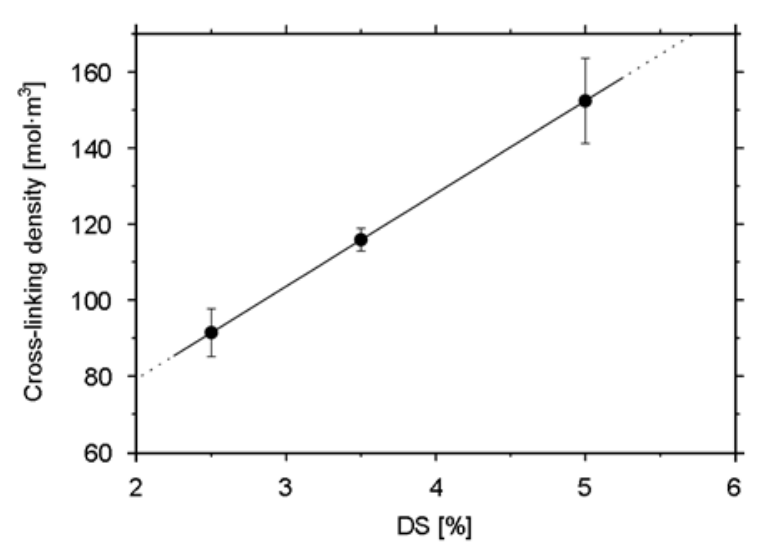

Figure 6. Cross-linking density, $v_{\mathrm{e}}$, as function of DS of PVA-GMA100 hydrogels

Table 2 shows the $v_{\mathrm{e}}$ and $M_{\mathrm{c}}$ values of PVA-GMA100 hydrogels along with the values of $\varphi_{2, \mathrm{r}}$ and $\varphi_{2, \mathrm{~s}}$.

The $v_{\mathrm{e}}$ and $M_{\mathrm{c}}$ for PVA-GMA/CS hydrogels were not calculated due to the ambiguity on calculation caused by contribution of CS to these parameters. The plot of $v_{\mathrm{e}}$ of PVA-GMA100 hydrogels as a function of the DS values of parents PVA-GMA
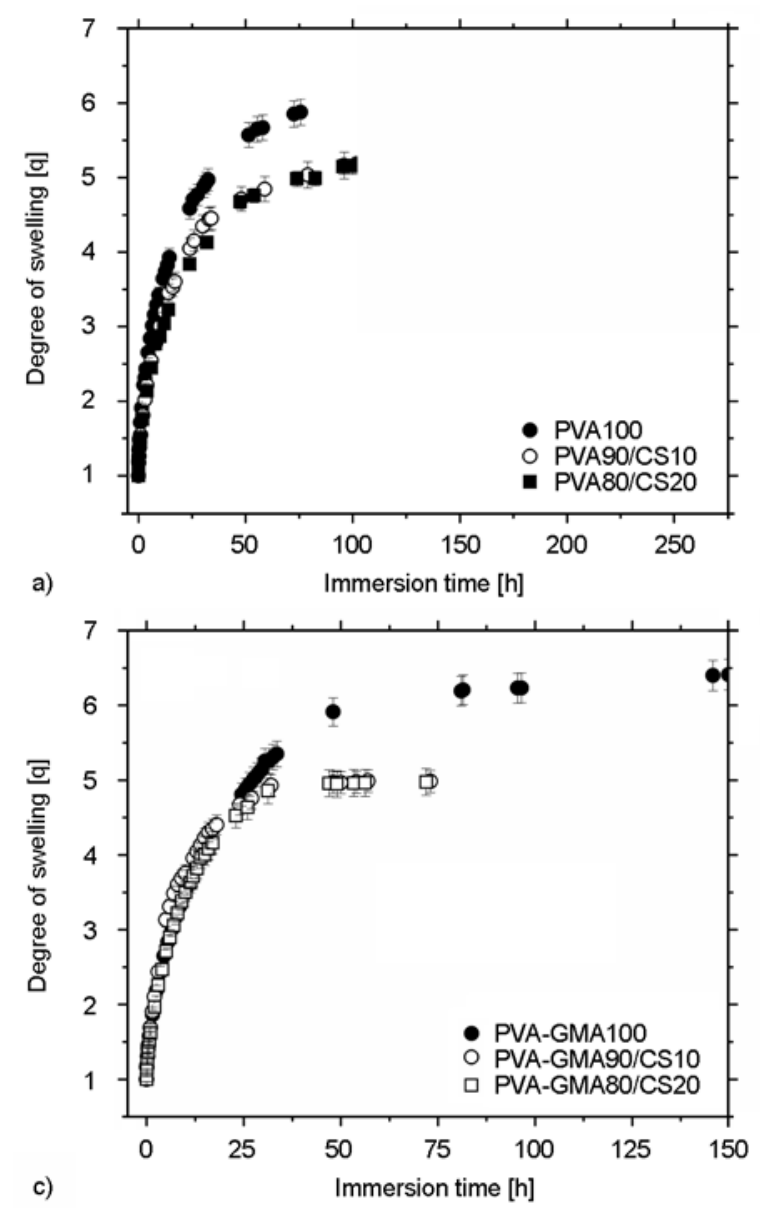

produced a straight line (see Figure 6). The line extrapolated for DS equal to 0 provides the net contribution of PVA-GMA chain entanglements to $v_{\mathrm{e}}^{0}$ which was ca. $30.5 \mathrm{~mol} \cdot \mathrm{m}^{-3}$. It should be emphasized that the chain entanglements affect positively the $E$ values and, consequently, improve the hydrogel mechanical properties as well [38].

\subsection{Swelling kinetics}

The curves of $q$ as a function of immersion time in SGF (pH 1.2) for PVA-GMA100, PVA-GMA90/ CS10 and PVA-GMA80/CS20 hydrogels are presented in the Figure $7 \mathrm{a}(\mathrm{DS}=2.5 \%)$ and in the Figure $7 \mathrm{~b}(\mathrm{DS}=5.0 \%)$. By comparison of the different curves of $q v s$. immersion time presented in the Figure 7a (SGF, pH 1.2), a negative effect on $q$ values caused by presence of CS can be observed. This effect is opposite to that observed for immersion of hydrogels in pure water (see Figure 3) and is attributed to ionization of carboxylic groups of CS in water, while the lowering the amount of charged
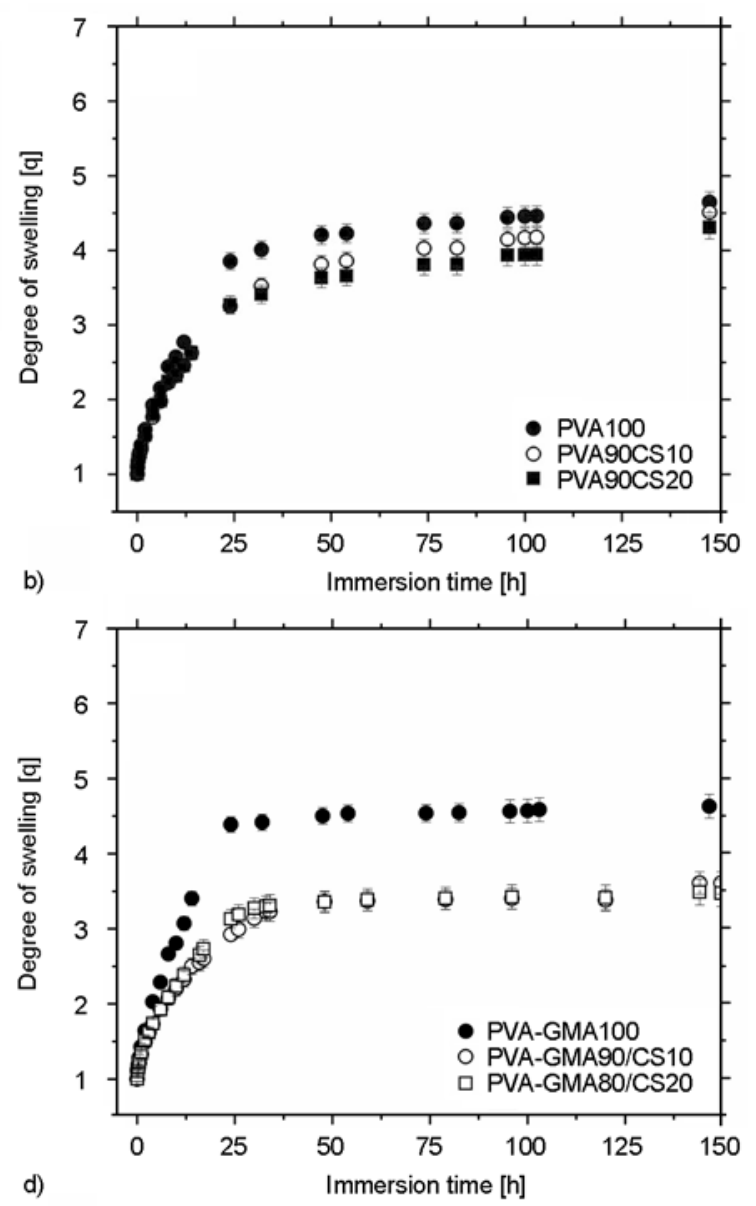

Figure 7. Degree of swelling as a function of immersion time in SGF (pH 1.2) at $37^{\circ} \mathrm{C}$ of PVA-GMA100, PVAGMA90/CS10, and PVA-GMA80/CS20 hydrogels samples with DS = 2.5 (a) and 5.0\% (b) and in SIF (pH 7.5) at $37^{\circ} \mathrm{C}$ of PVA-GMA100, PVA-GMA90/CS10, and PVA-GMA80/CS20 hydrogels samples (c) DS = 2.5 and (d) $\mathrm{DS}=5.0 \%$ 
moieties on $\mathrm{CS}$ at $\mathrm{pH}$ 1.2. In this situation, there is no significant repulsion among the CS segments. A common characteristic of ionic hydrogels is the repulsion of charged segments, which enhances the water, and other fluids, uptake capacity [39]. Curves similar to those shown in the Figure 7a were also obtained for PVA-GMA100, PVA-GMA90/CS10, and PVA-GMA80/CS20 hydrogels at DS $=3.5 \%$ (not shown here). However, the profile of $q v s$. immersion time of PVA-GMA and PVA-GMA/CS hydrogels as the DS of parent PVA-GMA was fixed at $5.0 \%$ is noticeably different, as shown in the Figure $7 \mathrm{~b}$. The $q$ values at $\mathrm{DS}=5.0 \%$ are remarkably lower and the equilibrium swelling is reached faster than at DS $=2.5 \%$. The increase in cross-linking density of ca. $60 \mathrm{~mol} \cdot \mathrm{m}^{-3}$ for a DS change from 2.5 to $5.0 \%$ (see Figure 6 ) accounts for the additional matrix compaction and leads to an opposite net effect on swelling.

The curves of $q$ as a function of immersion time in SIF ( $\mathrm{pH}$ 7.5) for PVA-GMA100, PVA-GMA90/ CS10 and PVA-GMA80/CS20 hydrogels are presented in the Figure 7c (DS $=2.5 \%)$ and the Figure $7 \mathrm{~d}(\mathrm{DS}=5.0 \%)$. At the beginning, being the carboxylic groups either totally or partially charged in SIF we expected an enhancement in $q$ compared to SGF. In fact, the results show that equilibrium $q$ values in SIF are almost the same as compared to the respective ones when swelled in SGF, but the equilibrium reached faster in SIF as compared to SGF.

It was expected that the swelling degree in Figure $7 \mathrm{~d}$ for SIF would be higher than at SGF (Figure $7 \mathrm{~b}$ ). This unexpected finding is under investigation. There are two different possibilities: one of them is the degradation of matrix (no apparent signal of degradation was observed). Another would be the release of chondroitin sulfate out of 3D matrix (the authors also have no evidence for that). It should be emphasized that PVA-GMA100 and PVA-GMA/CS hydrogels did not present apparent degradation under SIF or SGF swelling during $150 \mathrm{~h}$ after the immersion. The values of $k$ and $n$ obtained from Equation (2) for SGF and SIF are shown in Tables 3 and 4 for SGF (pH 1.2) and SIF ( $\mathrm{pH} 7.5)$, respectively. The $k$ values at SIF are higher than those calculated at SGF. This indicates a higher speed in swelling at higher $\mathrm{pH}$-condition. The main reason is the complete ionization of side groups on CS leading to repulsion among the CS chains at SIF. In spite of that, the PVA-GMA/CS hydrogels presented almost the same $q$ values in SGF as compared to SIF.

The values of $n$ for the hydrogels ranged from 0.54 to 0.59 as swelled in SGF and from 0.55 to 0.62 as swelled in SIF. As pointed out by Ritger and Peppas [40], $n$ values ranged from 0.45 to 1.0 for cylindrical hydrogels indicate anomalous mechanisms of transport during swelling. In this case, both diffusion and chain relaxation govern the fluid transport into hydrogel [40]. Drugs are more easily released out from hydrogel as the matrix is highly swelled than as compacted. Therefore, it is important to know the kinetic of swelling in drug carrier systems because the drug release rate is related to.

\subsection{Hydrogel morphology by SEM}

The effect of CS on hydrogel porosity relative to their respective PVA-GMA100 matrix, as control, was analyzed by SEM. Figure 8 presents the images

Table 3. Swelling kinetics parameters, $k$ and $n$, for PVA-GMA100, PVA-GMA90/CS10, and PVA-GMA80/CS20 hydrogels samples in SGF ( $\mathrm{pH} \mathrm{1.2)} \mathrm{at} 37^{\circ} \mathrm{C}$

\begin{tabular}{|c|c|c|c|c|c|c|}
\hline \multirow{2}{*}{$\begin{array}{c}\text { DS } \\
{[\%]}\end{array}$} & \multicolumn{2}{|c|}{ PVA-GMA100 } & \multicolumn{2}{c|}{ PVA-GMA90/CS10 } & \multicolumn{2}{c|}{ PVA-GMA80/CS20 } \\
\cline { 2 - 7 } & $\mathbf{k}\left[\mathbf{1 0}^{\mathbf{- 1}}\right]$ & $\mathbf{n}$ & $\mathbf{k}\left[\mathbf{1 0}^{-\mathbf{1}}\right]$ & $\mathbf{n}$ & $\mathbf{k}\left[\mathbf{1 0} \mathbf{-}^{-\mathbf{1}}\right]$ & $\mathbf{n}$ \\
\hline 2.5 & $1.50 \pm 0.16$ & $0.535 \pm 0.013$ & $1.16 \pm 0.10$ & $0.567 \pm 0.001$ & $1.22 \pm 0.13$ & $0.552 \pm 0.004$ \\
\hline 3.5 & $1.69 \pm 0.56$ & $0.593 \pm 0.024$ & $1.19 \pm 0.07$ & $0.572 \pm 0.001$ & $1.25 \pm 0.09$ & $0.546 \pm 0.005$ \\
\hline 5.0 & $1.18 \pm 0.09$ & $0.581 \pm 0.004$ & $1.19 \pm 0.23$ & $0.563 \pm 0.002$ & $1.29 \pm 0.26$ & $0.554 \pm 0.010$ \\
\hline
\end{tabular}

Table 4. Swelling kinetics parameters, $k$ and $n$, for PVA-GMA100, PVA-GMA90/CS10, and PVA-GMA80/CS20 hydrogels samples in SIF (pH 7.5) at $37^{\circ} \mathrm{C}$

\begin{tabular}{|c|c|c|c|c|c|c|}
\hline \multirow{2}{*}{$\begin{array}{c}\text { DS } \\
{[\%]}\end{array}$} & \multicolumn{2}{|c|}{ PVA-GMA100 } & \multicolumn{2}{c|}{ PVA-GMA90/CS10 } & \multicolumn{2}{c|}{ PVA-GMA80/CS20 } \\
\cline { 2 - 7 } & $\mathbf{k}\left[\mathbf{1 0}^{-\mathbf{1}}\right]$ & $\mathbf{n}$ & $\mathbf{k}\left[\mathbf{1 0}^{-\mathbf{1}}\right]$ & $\mathbf{n}$ & $\mathbf{k}\left[\mathbf{1 0} \mathbf{-}^{-\mathbf{1}}\right]$ & $\mathbf{n}$ \\
\hline 2.5 & $1.33 \pm 0.07$ & $0.560 \pm 0.002$ & $1.55 \pm 0.26$ & $0.589 \pm 0.039$ & $1.39 \pm 0.21$ & $0.582 \pm 0.016$ \\
\hline 3.5 & $1.11 \pm 0.01$ & $0.558 \pm 0.008$ & $1.36 \pm 0.01$ & $0.553 \pm 0.002$ & $1.32 \pm 0.11$ & $0.578 \pm 0.010$ \\
\hline 5.0 & $1.47 \pm 0.24$ & $0.616 \pm 0.023$ & $1.39 \pm 0.16$ & $0.572 \pm 0.004$ & $1.43 \pm 0.14$ & $0.585 \pm 0.010$ \\
\hline
\end{tabular}




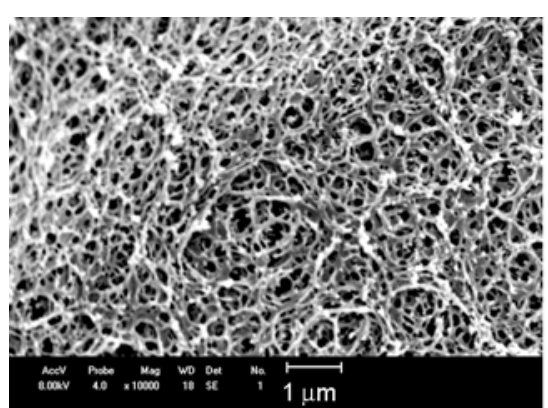

i(a)

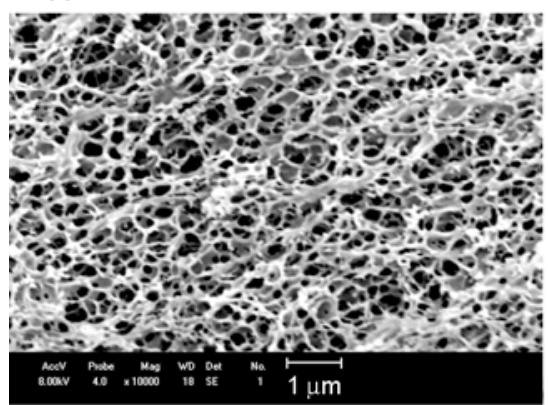

i(b)

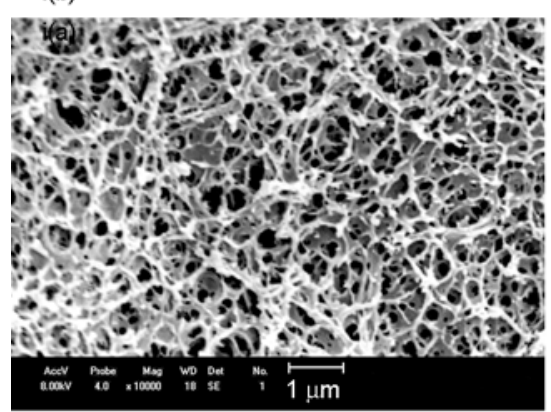

$\mathrm{i}(\mathrm{c})$

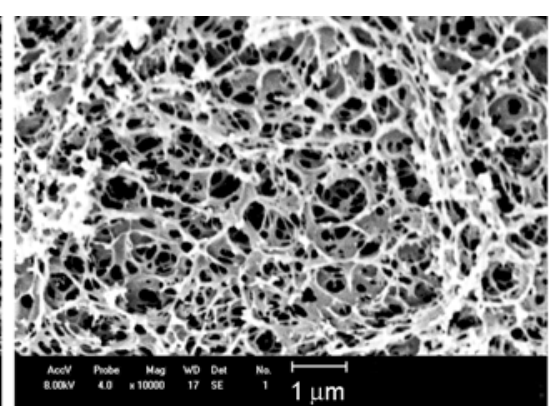

ii(a)

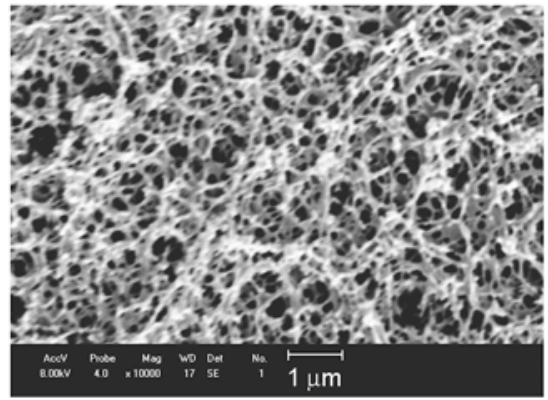

ii(b)

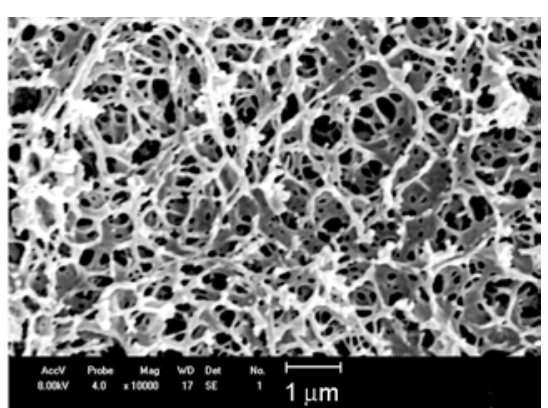

iii(a)

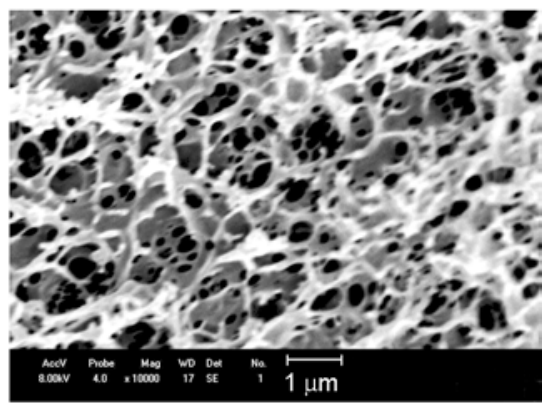

iii(b)

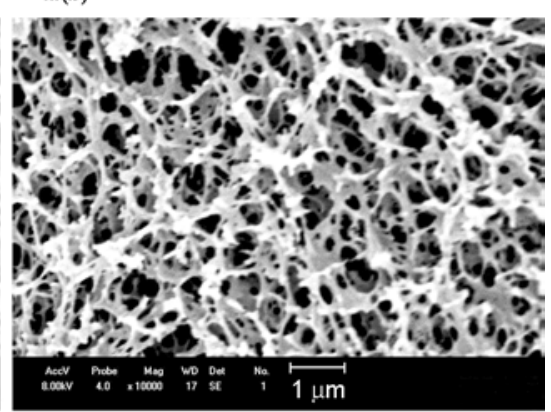

iii(c)

Figure 8. SEM images of PVA-GMA100 (i(a-c)), PVA-GMA90/CS10 (ii(a-c)), PVA-GMA80/CS20 (iii(a-c)) at DS 2.5\% (i-iii(a)), 3.5\% (i-iii(b)), and 5.0\% (i-iii(c)). Magnification: $10000 \times$.

obtained at 10000 -fold magnification of PVAGMA100 (i(a-c)), PVA-GMA90/CS10 (ii(a-c)), PVA-GMA80/CS20 (iii(a-c)) hydrogels made from precursor PVA-GMA with DS $=2.5 \%$ (i-iii(a)), 3.5\% (i-iii(b)), and 5.0\% (i-iii(c)). As can be seen, the presence of CS causes pore enlargement; however, the distribution remains inhomogeneous in all cases. For PVA-GMA90/CS10 and PVA-GMA80/CS20 hydrogels at DS $5.0 \%$, the morphology seems to be foliaceous. At DS 2.5 and 3.5\%, it was expected to obtain less porous hydrogels than the respective PVA-GMA100 but it was not verified. The reason for that is as follows: the PVA-GMA100 hydrogel at $\mathrm{DS}=5.0 \%$ gels up to $30 \mathrm{~s}$ after the addition of persulfate, while the PVA-GMA100 hydrogels at $\mathrm{DS}=2.5$ and $3.5 \%$ gel ca. 3 min after the addition of persulfate. In this way, PVA-GMA hydrogels at DS 5.0\% tend to present higher heterogeneity in pore sizes. Another possible contributing factor is the buildup in viscosity due to the presence of CS in PVA-GMA/CS hydrogels. Micro-heterogeneity enhances pore size in hydrogels [41]. Plenty of hydrogels with different porous sizes have been published in the literature [42] and in smart-hydrogels, the porous size can be controlled by external stimuli as temperature [43], $\mathrm{pH}$ [44], electrical discharge [45], to notice only few of them.

From the SEM images showed in Figure 8, the average pore size of each hydrogel samples was estimated through the computational software Size Meter $^{\circledR}$, version 1.1 with differentiation threshold set according to the image scale. Since the pore shape was undefined, the measurements were taken between the extreme points of the pores. The average was calculated from the measurement of 100 randomly selected pores. The results are shown in Table 5. 
Table 5. Average pore size of the hydrogel samples

\begin{tabular}{|l|c|c|}
\hline \multicolumn{1}{|c|}{ Sample } & DS & Average Pore Size $[\boldsymbol{\mu m}]$ \\
\hline PVA-GMA100 & 2.5 & $0.2617 \pm 0.0107$ \\
\hline PVA-GMA90/CS10 & 2.5 & $0.3177 \pm 0.0445$ \\
\hline PVA-GMA80/CS20 & 2.5 & $0.3683 \pm 0.0238$ \\
\hline PVA-GMA100 & 3.5 & $0.3053 \pm 0.0123$ \\
\hline PVA-GMA90/CS10 & 3.5 & $0.3009 \pm 0.0096$ \\
\hline PVA-GMA80/CS20 & 3.5 & $0.3670 \pm 0.0443$ \\
\hline PVA-GMA100 & 5.0 & $0.3195 \pm 0.0176$ \\
\hline PVA-GMA90/CS10 & 5.0 & $0.3650 \pm 0.0306$ \\
\hline PVA-GMA80/CS20 & 5.0 & $0.4376 \pm 0.0400$ \\
\hline
\end{tabular}

\subsection{Evaluation of hydrogel cytotoxicity}

The evaluation of cytotoxicity on PVA-GMA100, PVA-GMA90/CS10, PVA-GMA80/CS20 and PVAGMA67/CS33 hydrogels at DS 2.5, 3.5, or $5.0 \%$ were done through Vero cells culturing. Figure 9 presents the percentage of cell growth inhibition for each case, considering the number of cells in the positive control as $100 \%$ of inhibition.

Figure 9 evidences that the hydrogels are mostly non-toxic for Vero cells growth. In fact, PVA-GMA/ CS hydrogels presented lower inhibition capability than the PVA-GMA100 hydrogels did. The more intense effect was observed on hydrogel at high CS content. Such effect was attributed to the biological nature of CS, which is often found in animal extracellular matrix proteoglycans and considered as responsible for cell adherence and fixation. However, comparatively to the controls, cytotoxicity was slightly increased in hydrogels prepared at the precursor PVA-GMA.

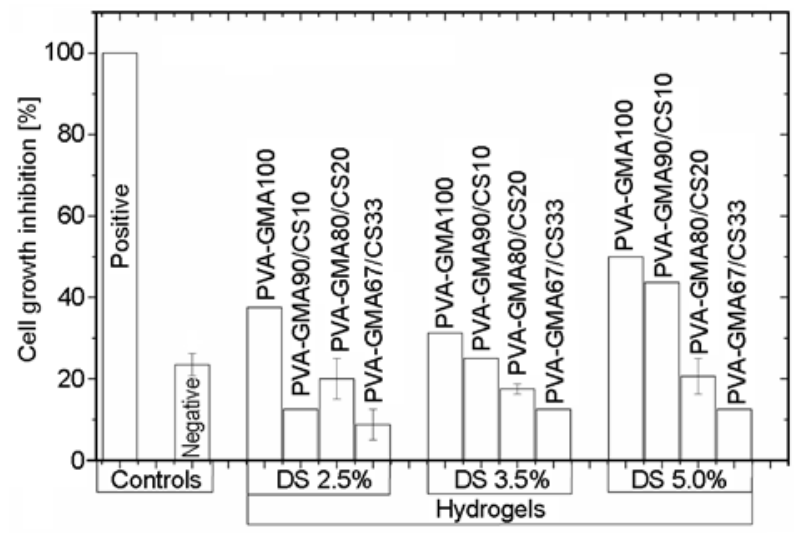

Figure 9. Cell growth inhibition (in \%) evaluated by nonviable cultured Vero cells count on the different hydrogels samples and controls as substrates

\section{Conclusions}

Hydrogels were prepared in presence of chondroitin sulfate (CS) at $0,10,20$ and $33 w t-\%$ by gelling of chemically modified poly(vinyl alcohol) (PVAGMA). Different degrees of substitution, DS, on PVA-GMA [2.5, 3.5 and 5.0\%] were achieved. The presence of CS into the hydrogels enhanced their hydrophilic feature and improved its cell viability. In addition, the hydrogels presented improved handling, except for PVA-GMA67/CS33. The values of elastic modulus, $E$, spread from 63 to $126 \mathrm{kPa}$ and are proportional to the DS of parent PVA-GMA, but they decrease slightly with the presence of CS. The hydrogels presented anomalous water uptake mechanism. Thus, Fickian diffusion and polymer chain relaxation govern the swelling of these hydrogels. PVA-GMA100 and PVA-GMA/CS hydrogels are resistant at $\mathrm{pH} 1.2$ (SGF) and $\mathrm{pH} 7.5$ (SIF). This interesting feature allows the hydrogels acting as a carrier for drug releasing in both media, protecting the drug against a degradation process, for example. Compared to the negative (polyethylene) and positive (silicon), used as controls, the presence of CS enhances the hydrogel-cell compatibility, results from cell viability tests. These results indicate the potential application of these materials as scaffolds in cell culture. Therefore, the PVA-GMA100 and PVA-GMA/CS hydrogels developed and characterized in this work present characteristics that allow them to be used as biomaterial, as a carrier in drug delivery system or to act as scaffolds in tissue engineering as well.

\section{Acknowledgements}

The authors thank Dep. de Ciência e Tecnologia de Alimentos (UEL, Londrina, Brazil) for the use of (TA.TXT2 Stable Micro System). The authors also thank to CNPq/Capes, Brazil, by the fellowships and financial support [Proc. 308611/2006-3].

\section{References}

[1] Hoffman A. S.: Hydrogels for biomedical applications. Advanced Drug Delivery Reviews, 54, 3-12 (2002). DOI: $10.1016 / \mathrm{S} 0169-409 \mathrm{X}(01) 00239-3$ 
[2] Byrne E. M., Park K., Peppas N. A.: Molecular imprinting within hydrogels. Advanced Drug Delivery Reviews, 54, 149-161 (2002).

DOI: 10.1016/S0169-409X(01)00246-0

[3] Krupa I., Nedelčev T., Račko D., Lacík I.: Mechanical properties of silica hydrogels prepared and aged at physiological conditions: Testing in the compression mode. Journal of Sol-Gel Science and Technology, 53, 107-114 (2010).

DOI: 10.1007/s10971-009-2064-5

[4] Oliveira J. T., Martins L., Picciochi R., Malafaya P. B., Sousa R. A., Neves N. M., Mano J. F., Reis R. L.: Gellan gum: A new biomaterial for cartilage tissue engineering applications. Journal of Biomedical Materials Research Part A, 93, 852-863 (2010).

DOI: $10.1002 / \mathrm{jbm} . \mathrm{a} .32574$

[5] Qiu Y., Park K.: Environment-sensitive hydrogels for drug delivery. Advanced Drug Delivery Reviews, 53, 321-339 (2001).

DOI: 10.1016/S0169-409X(01)00203-4

[6] Gutowska A., Bae Y. H., Jacobs H., Feijen J., Kim S. W.: Thermosensitive interpenetrating polymer networks: Synthesis, characterization, and macromolecular release. Macromolecules, 27, 4167-4175 (1994). DOI: $10.1021 / \mathrm{ma} 00093 \mathrm{a} 018$

[7] Cascone M. G., Barbani N., Giusti P., Cristallini C., Ciadelli G., Lazzeri L.: Bioartificial polymeric materials based on polysaccharides. Journal of Biomaterials Science, Polymer Edition, 12, 267-281 (2001). DOI: $10.1163 / 156856201750180807$

[8] Chiellini E., Cinelli P., Chiellini F., Imam S. H.: Environmentally degradable bio-based polymeric blends and composites. Macromolecular Bioscience, 4, 218 231 (2004).

DOI: 10.1002/mabi.200300126

[9] Zhang L., Yu P., Luo Y.: Dehydration of caprolactamwater mixtures through cross-linked PVA composite pervaporation membranes. Journal of Membrane Science, 306, 93-102 (2007).

DOI: $10.1016 /$ j.memsci.2007.08.036

[10] DeMerlis C. C., Schoneker D. R.: Review of the oral toxicity of polyvinyl alcohol (PVA). Food and Chemical Toxicology, 41, 319-326 (2003).

DOI: 10.1016/S0278-6915(02)00258-2

[11] Kelly C. M., DeMerlis C. C., Schoneker D. R., Borzelleca J. F.: Subchronic toxicity study in rats and genotoxicity tests with polyvinyl alcohol. Food and Chemical Toxicology, 41, 719-727 (2003).

DOI: $10.1016 / \mathrm{S} 0278-6915(03) 00003-6$

[12] Wang Y., Hsieh Y-L.: Crosslinking of polyvinyl alcohol (PVA) fibrous membranes with glutaraldehyde and PEG diacylchloride. Journal of Applied Polymer Science, 116, 3249-3255 (2010).

DOI: $\underline{10.1002 / a p p .31750}$
[13] Shaheen M. S., Yamaura K.: Preparation of theophylline hydrogels of atactic poly(vinyl alcohol)/ $\mathrm{NaCl} / \mathrm{H}_{2} \mathrm{O}$ system for drug delivery system. Journal of Controlled Release, 81, 367-377 (2000).

DOI: $10.1016 / \mathrm{S} 0168-3659(02) 00085-8$

[14] Kudo S., Otsuka E., Suzuki A.: Swelling behavior of chemically crosslinked PVA gels in mixed solvents. Journal of Polymer Science Part B: Polymer Physics, 48, 1978-1986 (2010). DOI: $10.1002 /$ polb.22076

[15] Reis A. V., Fajardo A. R., Schuquel I. T. A., Guilherme M. R., Vidotti G. J., Rubira A. F., Muniz E. C.: Reaction of glycidyl methacrylate at the hydroxyl and carboxylic groups of poly(vinyl alcohol) and poly(acrylic acid): Is this reaction mechanism still unclear? The Journal of Organic Chemistry, 74, 3750-3757 (2009). DOI: $10.1021 /$ jo900033c

[16] Valente A. J. M., Cruz S. M. A., Morán M. C., Murtinho D. B., Muniz E. C., Miguel M. G.: Release of DNA from cryogel PVA-DNA membranes. Express Polymer Letters, 4, 480-487 (2010).

DOI: 10.3144/expresspolymlett.2010.61

[17] Martens P., Anseth K. S.: Characterization of hydrogels formed from acrylate modified poly(vinyl alcohol) macromers. Polymer, 41, 7715-7722 (2000).

DOI: $10.1016 / \mathrm{S} 0032-3861(00) 00123-3$

[18] Reis A. V., Guilherme M. R., Mattoso L. H. C., Rubira A. F., Tambourgi E. B., Muniz E. C.: Nanometer- and submicrometer-sized hollow spheres of chondroitin sulfate as a potential formulation strategy for antiinflammatory encapsulation. Pharmaceutical Research, 26, 438-444 (2009).

DOI: $10.1007 / \mathrm{s} 11095-008-9732-y$

[19] Eastman S. A., Lesser A. J., McCarthy T. J.: Quantitative poly(vinyl alcohol) modification in ionic liquids: Esterification and urethanation with low surface tension producing reagents. Macromolecules, 43, 45844588 (2010).

DOI: $10.1021 / \mathrm{ma} 100458 \mathrm{v}$

[20] Zhao L., Xiong W., Liu M., Qi Z.: Study on superabsorbent of maleic anhydride/acrylamide semi-interpenetrated with poly(vinyl alcohol). Polymer for Advanced Technologies, 21, 483-489 (2010).

DOI: $10.1002 /$ pat.1456

[21] Gao B. J., Lu J. H., Zhuang R. B., Zhang G. H.: Preparation of poly(vinyl amine)-grafted crosslinked poly(vinyl alcohol) microspheres. Journal of Applied Polymer Science, 114, 3487-3494 (2009).

DOI: 10.1002/app.30892

[22] Ghugare S. V., Mozetic P., Paradossi G.: Temperaturesensitive poly(vinyl alcohol)/poly(methacrylate- $\mathrm{Co}-\mathrm{N}$ isopropyl acrylamide) microgels for doxorubicin delivery. Biomacromolecules, 10, 1589-1596 (2009).

DOI: $\underline{10.1021 / \mathrm{bm} 900185 \mathrm{u}}$ 
[23] Maris B., Verheden L., Van Reeth K., Samyn C., Augustijns P., Kinget R., Van den Mooter A.: Synthesis and characterisation of inulin-azo hydrogels designed for colon targeting. International Journal of Pharmaceutics, 213, 143-152 (2001).

DOI: $10.1016 / \mathrm{S} 0378-5173(00) 00654-2$

[24] Pitarresi G., Palumbo F. S., Giommona G., Casadei M. A., Micheletti Moracci F.: Biodegradable hydrogels obtained by photocrosslinking of dextran and polyaspartamide derivatives. Biomaterials, 24, 4301-4313 (2003).

DOI: 10.1016/S0142-9612(03)00332-6

[25] Lee C-T., Kung P-H., Lee Y-D.: Preparation of poly(vinyl alcohol)-chondroitin sulfate hydrogel as matrices in tissue engineering. Carbohydrate Polymers, 61, 348-354 (2005).

DOI: 10.1016/j.carbpol.2005.06.018

[26] Avci F. Y., Toida T., Linhardt R. J.: Chondroitin $O$ methyl ester: An unusual substrate for chondroitin AC lyase. Carbohydrate Research, 338, 2101-2104 (2003). DOI: 10.1016/S0008-6215(03)00348-3

[27] Kartal F., Akkaya A., Kilinc A.: Immobilization of porcine pancreatic lipase on glycidyl methacrylate grafted poly vinyl alcohol. Journal of Molecular Catalysis B: Enzymatic, 57, 55-61 (2009).

DOI: $10.1016 /$ j.molcatb.2008.06.016

[28] Iwafune M., Kakizaki I., Nakazawa H., Nukatsuka I., Endo M., Takagaki K.: A glycomic approach to proteoglycan with a two-dimensional polysaccharide chain map. Analytical Biochemistry, 325, 35-40 (2004).

DOI: 10.1016/S0003-2697(03)00391-9

[29] Crispim E. G., Piai J. F., Rubira A. F., Muniz E. C.: Addition of methacryloil groups to poly(vinyl alcohol) in DMSO catalyzed by TEMED: Optimization through response surface methodology. Polymer Testing, 25, 377-383 (2006).

DOI: $10.1016 /$ j.polymertesting.2005.12.003

[30] USP 23-NF18: U.S. Pharmacopeia: National formulary supplement. (1995).

[31] Lin C-C., Metters A. T.: Hydrogels in controlled release formulations: Network design and mathematical modeling. Advanced Drug Delivery Reviews, 58, 1379-1408 (2006).

DOI: $10.1016 /$ j.addr.2006.09.004

[32] Sperling L. H.: Introduction to physical polymer science. Wiley, New York (2006).

[33] Paradossi G., Cavalieri F., Capitani D., Crescenzi V.: Physicochemical characterization of chemical hydrogels based on PVA. Journal of Polymer Science Part B: Polymer Physics, 37, 1225-1233 (1999).

DOI: 10.1002/(SICI)1099-0488(19990615)37:12<1225 $\because$ AID-POLB4>3.0.CO;2-P

[34] ASTM-F813-01: Standard Practice for direct contact cell culture evaluation of materials for medical devices (2005).
[35] Malmonge S. M., Zavaglia C. A. C., Santos A. J., Wada M. L. F.: Citotoxicity evaluation for polyhema hydrogels: An in vitro study (in Portugese). Revista Brasileira de Engenharia Biomédica, 15, 49-54 (1999).

[36] Crispim E. G., Piai J. F., Schüquel I. T. A., Rubira A. F., Muniz E. C.: Functionalization of poly(vinyl alcohol) by addition of methacryloyl groups: Characterization by FTIR and NMR and optimization of reaction conditions by RSM. e-Polymers, no.62 (2006).

[37] Peppas N. A., Merril E. W.: Crosslinked poly(vinyl alcohol) hydrogels as swollen elastic networks. Journal of Applied Polymer Science, 21, 1763-1770 (1977).

DOI: 10.1002/app.1977.070210704

[38] Elias H. G.: Macromolecules: Structure and properties. Plenum Press, New York (1983).

[39] Fajardo A. R., Piai J. F., Rubira A. F., Muniz E. C.: Time- and $\mathrm{pH}$-dependent self-rearrangement of a swollen polymer network based on polyelectrolytes complexes of chitosan/chondroitin sulfate. Carbohydrate Polymers, 80, 934-943 (2010).

DOI: $10.1016 / \mathrm{j}$. carbpol.2010.01.009

[40] Ritger P. L., Peppas N. A.: A simple equation for description of solute release II. Fickian and anomalous release from swellable devices. Journal of Controlled Release, 5, 37-42 (1987).

DOI: 10.1016/0168-3659(87)90035-6

[41] Yoshinari E., Furukawa H., Horie K.: Fluorescence study on the mechanism of rapid shrinking of grafted poly $(N$-isopropylacrylamide) gels and semi-IPN gels. Polymer, 46, 7741-7748 (2005).

DOI: $10.1016 /$ j.polymer.2005.01.100

[42] Moura M. R., Guilherme M. R., Campese G. M., Radovanovic E., Rubira A. F., Muniz E. C.: Porous alginate- $\mathrm{Ca}^{2+}$ hydrogels interpenetrated with PNIPAAm networks: Interrelationship between compressive stress and pore morphology. European Polymer Journal, 41, 2845-2852 (2005).

DOI: $10.1016 /$ j.eurpolymj.2005.06.007

[43] Li Y., Zhang L., Zuo Y., Yang W. H., Shen J., Li Y.: Poly(N-isopropyl acrylamide)/chitosan composite membrane with smart thermoresponsive performance. Materials Research Innovations, 14, 252-257 (2010). DOI: $10.1179 / 143307510 X 12719005364828$

[44] You J-O., Auguste D. T.: Conductive, physiologically responsive hydrogels. Langmuir, 26, 4607-4612 (2010). DOI: 10.1021/la100294p

[45] Barthus R. C., Lira L. M., de Torresi S. I. C.: Conducting polymer- hydrogel blends for electrochemically controlled drug release devices. Journal of the Brazilian Chemical Society, 19, 630-636 (2008). DOI: $10.1590 / \mathrm{S} 0103-50532008000400004$ 